\title{
El paper de la mediació en el desenvolupament de la competència literària: Disseny i aplicació d'una intervenció didàctica
}

Vanesa Amat i Castells, Universitat de Vic, Espanya

\section{Introducció}

L'escola crea l'espai literari que fa possible concebre's com a lector en un marc cultural. C. Baudelot ${ }^{1}$

La tasca docent consisteix a dissenyar contextos, planificar i desenvolupar activitats, observar i avaluar les possibilitats d'aprenentatge que es generen a les aules, etc. de manera que sigui possible que els alumnes avancin en l'adquisició de competències en els diferents àmbits de coneixement. En el cas de l'aprenentatge literari, la formació de lectors que dominin patrons narratius i puguin gaudir de les lectures s'esdevé a partir de les possibilitats que els adults ofereixen als infants en un context cultural determinat, però quin tipus de pràctiques poden resultar més útils? Quines característiques han de tenir les propostes que s'ofereixen i quin paper ha d'exercir el docent en el seu desenvolupament?

\section{El diàleg en el desenvolupament de la competència literària}

Les aportacions de disciplines com la psicologia cognitiva d'enfocament social han valorat la conversa ${ }^{2}$ com un espai privilegiat per desenvolupar aprenentatges en el context escolar, entenent aquest tipus d'activitats d'intercanvi oral com a context natural d'intervenció, tot i que no totes les converses esdevenen pràctiques que permeten desenvolupar aprenentatge, ni existeix un únic tipus de conversa que es pugui aplicar en qualsevol context.

Les pràctiques reflexives portades a terme en l'àmbit escolar generen preguntes sobre quines són les característiques de la conversa que afavoreixen l'aprenentatge: quin tipus d'interacció sembla més productiva en aquest sentit, quin és el paper del mestre en les discussions o si es poden establir pautes d'actuació o elaborar instruments que 
permetin millorar les converses entre el mestre i els alumnes o entre iguals (Ribas i Vilà 2005).

De fet, tan sols parlar en veu alta per expressar les pròpies opinions, verbalitzarles, esdevé un acte reflexiu important que ajuda a elaborar el propi pensament. El diàleg fa possible que els infants hagin d'organitzar les seves idees per transmetre-les públicament. "El efecto público es que al poner sobre la mesa nuestros pensamientos ampliamos nuestra habilidad para pensar" (Chambers 2007a: 33). Els alumnes aprenen parlant i esdevenen constructors actius dels seus propis aprenentatges (Wells 1988). L'intercanvi, a més, fa possible compartir elaboracions personals i transformar-les a través del contacte amb les aportacions dels altres.

Malgrat que encara s'han portat a terme poques recerques on s'observa el tipus d'intercanvis que es produeixen mentre els lectors discuteixen sobre literatura, sembla haver-hi un cert consens entre autors que han indagat en els aspectes d'adquisició de competències en l'àmbit literari - Chambers 2007a; Siro 2005; Colomer 2005a, 2005b; Kiefer 1999, etc.- per tal d'establir la necessitat d'aquest tipus de pràctiques, que permeten contrastar opinions i reformular pensaments sobre les obres i els seus elements constitutius (Manresa i Silva-Díaz 2005).

El diàleg, com a acte social, permet compartir l'entusiasme que han suscitat les obres, recordant el que s'ha esdevingut en la lectura i comentant els elements, de qualsevol tipus, que els han agradat; compartir els desconcerts que els ha generat la lectura com una forma d'endinsar-se en un terreny compartit per anar a la discussió del sentit, interpretant els aspectes que configuren l'obra -considerant que els significats compartits canvien d'acord amb el context de la vida dels lectors i de les seves necessitats en un moment determinat- i compartir connexions, quan els alumnes cerquen relacions i construeixen patrons literaris a partir de la memòria de les pròpies vides i dels elements que han detectat en altres lectures (Chambers 2007b).

Sembla necessari desenvolupar espais de lectura a l'escola tal com funciona socialment, en un clima propici al comentari, a la recomanació i a l'intercanvi. En molts casos, en les discussions en què intervé la totalitat d'alumnat és gairebé inevitable que molts actuïn tan sols com a oients $i$, malgrat que aquest fet no significa que no es produeixi una actitud d'escolta activa que permeti l'aprenentatge, poder dialogar en petits grups garanteix la possibilitat que els alumnes interactuïn més entre ells i 
participin més activament, elaborant les seves intervencions, en un ambient afectiu, favorable a les descobertes.

\section{El paper de la mediació en les activitats de diàleg per a l'aprenentatge literari}

Aprendre a interpretar i a gaudir de les lectures literàries implica un determinat paper de l'adult que exerceix de mediador. La construcció de l'aprenentatge literari, com tots els aprenentatges significatius, parteix de l'alumne, dels seus coneixements previs, dels seus interessos, de les seves inquietuds, però requereix de la tasca orientadora $\mathrm{i}$ estimulant de l'adult:

Aprendre és una activitat constructiva que ha de dur a terme l'aprenent. Per a aquesta tasca, però, resulta indispensable la intervenció de l'adult, que ha d'exercir una funció de mediador a partir dels coneixements que l'alumne posseeix (Camps i Colomer 1998, 81).

En aquest sentit, el mestre té la responsabilitat d'aplicar estratègies que permetin guiar i potenciar el desenvolupament de les habilitats i les capacitats de l'alumne. Centrant l'atenció en les pràctiques escolars d'ensenyament - aprenentatge de la literatura es fa evident que, en molts casos, es continua produint la transmissió de conceptes literaris i d'interpretacions textuals de manera asimètrica: del docent a l'alumne, de l'expert a l'aprenent. Així doncs, és freqüent que a l'aula el mestre formuli qüestions encaminades a conèixer el grau de comprensió d'una lectura o el nivell d'interpretació d'un element simbòlic de tal manera que l'alumne esdevingui un agent passiu en el seu propi procés d'aprenentatge.

Wells (1988) exemplifica aquesta qüestió a partir de l'observació del comentari d'un conte a l'aula, en què es mostra com la mestra interroga als alumnes sobre la lectura amb la intenció que responguin ajustant-se als paràmetres d'interpretació que ella ha seguit, intentant que descobreixin què pensa. Es tracta d'una situació freqüent a l'escola, que crea una relació educativa fonamentada en la dependència dels alumnes cap al mestre a l'hora d'accedir al text. El mediador descobreix noves interpretacions en els comentaris dels alumnes quan deixa de ser un simple instructor que coneix totes les possibles respostes abans de pronunciar-se.

En aquesta línia, el mestre hauria d'oferir l'ajuda necessària als alumnes i crear contextos rics i estimulants per tal que puguin desenvolupar el seu aprenentatge. Els 
mediadors haurien de fomentar espais on puguin aparèixer els interessos dels infants $\mathrm{i}$ ajudar a ampliar-los i a desenvolupar-los per crear sentits:

La responsabilidad es clara: interactuar con aquellos que están a nuestro cuidado de un modo tal que fomente y enriquezca su elaboración de significaciones (Wells 1988:267).

En les reflexions al voltant del paper del mediador en espais de discussió es plantegen distintes possibilitats: el desenvolupament lliure de la conversa entre alumnes amb la figura d'un mediador inexistent, un intercanvi dirigit absolutament pel docent o bé una discussió semidirigida en què el mestre adopta el paper d'orientador en diversos graus. Sembla que una de les fórmules més efectives parteix de la figura del mestre exercint el rol de moderador, de tal manera que els alumnes se sentin lliures a l'hora d'expressar les seves opinions sobre la lectura. En el desenvolupament de les converses, el mestre podrà formular qüestions més específiques, que permetin centrar el diàleg en l'anàlisi dels elements que configuren l'obra per tal de progressar en la creació de sentits, en l'adquisició de la competència literària. Es tracta que els alumnes puguin començar expressant aspectes obvis per anar avançant, amb l'ajuda de l'adult, en la descoberta de sentits més profunds, que precisen de més elaboració: "Es al compartir lo obvio cuando empezamos a pensar lo que ninguno de nosotros ha pensado antes" (Chambers 2007b: 68).

Tanmateix, destaca la importància que el docent escolti atentament els interrogants que els alumnes generen a partir de les seves pròpies reflexions. Tan sols si el mediador és capaç d'escoltar i tenir en compte les aportacions dels alumnes podrà orientar-los en la construcció d'aprenentatges metaliteraris, de reflexió sobre la pròpia literatura:

Es necesario que el mediador oriente la reflexión metaliteraria al servicio de comprender mejor el sentido de la obra [...]. Reflexionar sobre ciertos recursos tiene sentido para el lector en tanto herramientas de construcción de significado (Siro 2005: 51).

Per tant, la tasca de moderador del mestre es caracteritza per deixar espais de temps perquè els alumnes puguin expressar-se, rellegir, remirar, analitzar o comparar (Kiefer 1999), però també és necessari que el docent faciliti la creació de processos d'aprenentatge, ajudant a reconsiderar o aprofundir reflexions, ampliant i difonent les respostes lectores: 
Si la literatura ofereix una manera articulada de reconstruir la realitat, de gaudirne estèticament, d'explorar els propis punts de vista a través de la presentació d'alternatives, la clarificació dels punts foscos o la reconciliació dels conflictes en l'interior d'una experiència personal i subjectiva, el paper de l'ensenyant en aquest procés hauria de ser principalment el de qüestionar i expandir les respostes, el d'aclarir la representació de la realitat que l'obra ha intentat construir, més que el d'ensenyar principis o categories d'anàlisi (Colomer 1998: 109).

\section{Breu relat d'una experiència didàctica: La creació d'un recurs per fomentar el diàleg en clau literària}

L'aplicació d'una intervenció didàctica per aprendre literatura amb alumnat de segon curs de Primària (7-8 anys) es planteja a partir del diàleg en grups de quatre infants ${ }^{3}$ al voltant de la lectura d'àlbums il·lustrats ${ }^{4}$. Les converses es plantegen amb l'objectiu d'intercanviar impressions sobre les lectures i fer descobertes dels elements literaris que configuren els àlbums (Amat 2010). Inicialment es constaten les dificultats que els alumnes tenen a l'hora de parlar de les obres, sol-liciten l'ajuda de la mestra, preguntant què és el que han de dir, i es miren entre ells mostrant el seu desconcert. Esperen preguntes concretes sobre les lectures per part de la docent $i$ en molts casos es limiten a elaborar un resum, més o menys ben articulat, amb les accions essencials que constitueixen l'argument de l'obra, probablement perquè aquest és el tipus de tasca que estan acostumats a realitzar al voltant de la lectura, responent segons els paràmetres que els mestres els dicten, expressant, sense intercanviar, el que és més rellevant de la història, intentant demostrar el grau de comprensió lectora.

La planificació d'activitats de diàleg parteix de la necessitat de fer “(...) intercanvis que afavoreixen les estratègies interpretatives, crítiques i inferencials, amb atenció als aspectes estètics i emocionals" (Colomer 2009:10). Aquest tipus de pràctiques, però, requereixen l'ús de materials que puguin facilitar l'expressió i la construcció d'idees metaliteràries al voltant de les obres i fomentar l'autonomia en els intercanvis.

En aquest sentit es realitza una pauta que recull idees organitzades per blocs segons els temes i es penja en un racó de l'aula. El material es planteja com una proposta oberta amb oracions exposades de forma senzilla, que puguin ser clares pels infants, al voltant del text, els personatges, els elements estètics i la recepció de les 
obres $^{5}$. Es tracta d'una eina que pretén ser un suport, de manera que els alumnes la puguin utilitzar si els sembla necessari, però que, en cap cas, estan obligats a seguir.

Disposar d'aquest recurs, saber que en podran fer ús, els dóna confiança per expressar-se. En el moment de presentar el material a l'aula els infants formulen expressions com: "Això ho tindrem sempre per mirar-ho?" o "ho podrem copiar si volem dir una d'aquestes coses?" que indiquen la sorpresa que els causa utilitzar un material que no pretén avaluar-los i la tranquil-litat de tenir un recull de propostes per fer servir en el cas de necessitar-ho. Sovint els mestres es mostren reticents a fer ús d'aquest tipus d'instrument amb la idea que els alumnes reproduiran les oracions del material i aquest fet limitarà la possibilitat d'aportacions personals. En l'afany de control i supervisió de l'adult, en ocasions, es perd la possibilitat de generar aprenentatges nous fomentant l'autonomia de l'infant.

Així doncs, per afavorir l'aprenentatge sembla interessant que la pauta no sigui un element avaluador sinó que estigui plantejada de manera que faciliti la pràctica, com a guia. Aquesta flexibilitat permet que els alumnes no es trobin sotmesos a respondre només les qüestions que la mestra proposa i puguin plantejar l'orientació de la conversa a partir de la seva pròpia recepció.

Durant les discussions, algunes de les qüestions de la pauta serveixen de guia en el moment en què els alumnes proposen temes o exposen idees. N'és una mostra el fragment següent que reprodueix un moment de la discussió en què els alumnes destaquen un element del text (veure l'apèndix pels criteris de transcripció):

MARC: El text m'ha agradat molt perquè estava molt ben explicat i a més les paraules que feia amb els sons

PAULA: A mi també m'han agradat les paraules sobretot quan li feia aixins el seu avi plush plush (acluca l'ull)

(Tots busquen les pàgines on hi ha onomatopeies)

El fet de destacar un element del text es recull a la pauta ("hi ha rodolins, jocs de paraules...”) i permet centrar l'atenció en un joc lingüístic suggerent lligat a l'aspecte literari de l'obra llegida. En la primera discussió en petit grup que es produeix al voltant d'aquest mateix àlbum, sense l'ús de la pauta, els alumnes no fan cap referència a aquest element i els costa començar l'intercanvi d'idees més enllà de formular breus 
resums de l'obra. Sembla, doncs, que aquest recurs pot ser útil com a punt de partida de la conversa en clau literària.

En diverses ocasions els infants seleccionen frases, expressions lingüístiques, com onomatopeies, o escullen un dibuix, tal com es proposa a la pauta. Aquestes eleccions permeten focalitzar l'atenció en elements concrets que configuren els àlbums il-lustrats i apropar-se a la forma en què transmeten significats. N'és un exemple el fragment de conversa següent:

CÈLIA: A mi m'agrada aquesta serp de mar

MIQUEL: A mi també $\downarrow$

CÈLIA: Que diu aquesta frase que se li escapa la cua per si la perd

PEP: A mi m’ha fet molt riure (@aquestes algues que diuen que són de sucre)

MIQUEL: Pedres de sucre diuen que són perquè com que s'ho imagina

CÈLIA: I tant $\downarrow$

PEP: És imaginació

CÈLIA: Tot és imaginació de sucre

PEP: És fantasia

La fantasia que transmeten les paraules a partir de metàfores que els alumnes saben detectar i apreciar en espais d'intercanvi en què es poden expressar a partir de les indicacions obertes que els ofereix la pauta (“'m'agrada aquesta frase...”).

En Marc també focalitza l'atenció en una de les frases del text, concretament la del final, i així la mestra pot recollir la seva aportació per incidir en algunes qüestions:

MARC: A mi m'ha agradat molt la frase quan ha dit que el trajecte del tren no s'acabaria mai

MESTRA: Què deu ser això $\uparrow$

SERGI: Que els dos fils els podria(..) no se'ls acabaria mai, els podria fer tot el temps que volgués

Es tracta d'una oració que transmet un final obert, que suggereix interpretacions diferents, de caràcter poètic, i que permet endinsar-se en la comprensió d'un element 
literari important, com és el desenllaç, que implica posar en joc els propis coneixements del món i la pròpia experiència lectora, a més d'establir relacions amb el conjunt de l'obra, per atorgar sentit a la lectura.

L'aportació que en Sergi extreu de la pauta al voltant del paper que poden tenir les il·lustracions en la transmissió del sentit de l'àlbum ("els dibuixos m'han ajudat/no m'han ajudat a entendre la història") genera un intercanvi d'opinions interessant:

SERGI: Lo què m'ha costat d'entendre ha set una mica els dibuixos no m'han ajudat gaire a entendre el conte

MARC: Perquè els dibuixos estan molt ben fets però no s'entenen gaire

SERGI: Ja perquè són fets amb esponges

L'exemple mostra com els infants interpreten el codi visual, realista o abstracte, a partir d'una idea que es recull del llistat i que origina reflexions sobre els motius pels quals les il·lustracions, i la tècnica $a m b$ què s'han creat, desenvolupen unes determinades funcions en un àlbum ${ }^{6}$.

El fet de destacar un element de l'obra i intentar fer-ne una interpretació, lligada a les impressions o emocions personals, a la pròpia recepció, permet avançar en la complexitat d'entendre la creació literària. La pauta també resulta útil per respondre les preguntes de la mestra:

MESTRA: Per què penseu que algun altre nen o nena l'hauria de llegir $\uparrow$ Si és que penseu que algú l'hauria de llegir $\uparrow$

MIQUEL: Perquè el final et fa sentir alegre

PEP: Fa sentir sentiments

Els motius per recomanar una lectura poden ser diversos, però el fet de poder precisar que un element clau, escollit de la pauta (“el final et fa sentir..."), és la producció d'un determinat sentiment significa prendre consciència del valor que té la literatura.

En aquesta mateixa línia, la situació següent permet reflexionar sobre la manera en què la docent inicia la conversa amb la intenció de conèixer la recepció més personal 
de l'obra i com, després d'una resposta breu, en Miquel acota la seva primera aportació utilitzant una idea del llistat referent al final:

MESTRA: Va com us ha fet sentir doncs la "Lluna d'en Joan" $\uparrow$

CÈLIA: A mi bé

MIQUEL: A mi bé $\downarrow$

XELL: A mi també $\downarrow$

MIQUEL: Bueno a mi el final m'ha fet sentir bé però mentres no tenia això del pare no tant

La mestra planteja un primer focus d'observació a partir de la seva interrogació però el que sembla rellevant és que l'alumne aprofundeix la seva reflexió utilitzant una qüestió que es recull a la pauta, centrant l'atenció en el desenllaç (“el final m’ha fet sentir..."). De fet, respondre a partir de les sensacions que produeix el final i adonar-se de com difereixen de les provocades en la resta de moments de la història ofereix la possibilitat d'observar el desenllaç com un element que dota de sentit tota la narració, que permet establir relacions amb les accions narrades i encaixar-les de manera que produeixi un determinat efecte. A continuació, es poden establir connexions amb les accions contades per anar desgranant aspectes sobre l'estructura de l'obra.

En el transcurs de les discussions la majoria d'idees que els alumnes comparteixen provenen de les seves preferències personals, d'elements que els han desconcertat o d'imatges i seqüències que els han sorprès i que, posades en comú, poden derivar cap a la construcció conjunta de sentits al voltant del fet literari. La pauta, lluny de limitar les possibilitats d'expressió dels alumnes, els guia en el transcurs del diàleg i el seu plantejament obert els permet iniciar noves observacions i construir reflexions al voltant de nous aspectes.

L'interès de la utilització d'una eina didàctica com la pauta recau en el fet que pot ajudar als alumnes a focalitzar l'atenció en elements literaris concrets que configuren un àlbum illlustrat, però sempre partint d'un enfocament lliure, respectant que l'infant pugui prendre les decisions sobre els temes a tractar, i en estreta relació amb els aspectes emocionals que suscita la lectura.

Aquest material pot ser útil com a punt de partida, com a referència, però també es pot contemplar la possibilitat que els alumnes puguin crear materials que recullin les 
propostes de temes plantejats per ells mateixos per tal de tenir-los recollits, expandir les seves respostes, compartir-les i recordar els moments d'intercanvi en què es construïren.

La pauta també esdevé útil per la mestra, que la pren com a referència en el moment de formular noves qüestions. D'aquesta manera, infants $\mathrm{i}$ docent poden disposar d'un recurs comú que els ajuda a desenvolupar la discussió, a enriquir-la, partint del fet de fixar l'atenció en elements literaris des de la llibertat d'elecció.

\section{Les intervencions docents en els intercanvis}

L'anàlisi de la pròpia actuació docent permet prendre consciència de la forma en què es gestionen els diferents factors que intervenen en una determinada situació educativa, amb la intenció de reflexionar sobre la manera en què es pot millorar la pràctica a l'aula. El grau de guiatge que exerceix la mestra en les discussions literàries esdevé clau en el desenvolupament d'aprenentatges; considerar el tipus de qüestions que formula i la manera com recull les aportacions dels alumnes és significatiu per tal de valorar el grau d'incidència de la figura docent.

Chambers (2007b) estableix la importància de començar amb una expressió oberta i receptiva que transmeti el desig de l'adult de restar obert a tot tipus d'aportacions dels alumnes, oferint-los temps per pensar. Així, sembla poc aconsellable iniciar la conversa amb l'ús de formes pròpies de l'ensenyament tradicional, com ara "per què...", “què significa?", “de què tracta realment?", que, pronunciades al principi de la discussió, esdevenen inhibidores i provoquen que els alumnes vulguin cercar respostes que siguin del gust del mestre, en lloc d'expressar les seves impressions a partir de les quals progressar en l'aprenentatge.

En aquesta línia, l'experiència portada a terme amb grups d'infants que conversen al voltant d'obres literàries mostra que iniciar les discussions amb preguntes genèriques i obertes, com “què us ha semblat?", “què voleu dir d'aquest llibre?" o "com us ha fet sentir?", amb l'objectiu d'acollir tot tipus d'aportacions dels alumnes permet que puguin expressar-se amb llibertat sobre qualsevol qüestió, que verbalitzin les preferències, els desconcertes, les impressions que els ha produït l'obra, que aflorin, també, els seus coneixements previs, sense estar sotmesos a les respostes que la mestra espera d'ells. Després d'un temps aplicant la rutina de la discussió els infants expressen les seves opinions abans que la mestra hagi pogut formular cap pregunta, situació que 
mostra el grau d'autonomia que adquireixen en la gestió de la dinàmica i l'interès que tenen a l'hora de compartir les pròpies percepcions.

La resposta afectiva per part de l'adult, que acull aportacions, somriu, assenteix i mira tots els infants, es planteja com una forma positiva d'intervenció per tal de crear un ambient que estimuli i fomenti la participació de tots. Els alumnes miren la mestra després d'expressar cada idea, cercant la seva aprovació, especialment en les primeres ocasions en què es porten a terme les converses, de manera que es fa evident la necessitat de mostrar-los una actitud receptiva que els doni confiança a l'hora d'expressar-se sense inhibicions.

Les intervencions docents no sempre són productives, generadores de possibilitats d'aprenentatge. S'esdevenen moments en què la mestra insisteix en alguna qüestió, que li sembla rellevant, formulant preguntes que intenten reconduir la situació, però la forma en què s'elaboren no acaba de resultar eficaç:

CLÀUDIA: Potser el noi- el noi no volia dibuixar tant $\mathrm{i}$ ha fet una nena petita així

MESTRA: Penseu que ha set per això que ho ha fet l'autor $\uparrow$

MARC: Potser era com jo que no li agrada dibuixar

MESTRA: @ Home i voleu- vols dir que no li agrada dibuixar i ha triat fer un conte [només amb dibuixos] $\uparrow$

PAULA: [ A mi el què no m’agrada] és pintar amb llapis ((@perquè si no se m'acaba la punta)

MESTRA: @ Si no li agradés dibuixar voleu dir que hauria fet un conte amb dibuixos només $\uparrow$

MARC: Ah sí $\downarrow$ però és que també són estranys perquè mira aquí hi ha el braç i en surten dos més aquí

Es mostra que la mestra repeteix la mateixa qüestió per intentar que els alumnes reflexionin sobre les decisions que pren l'autor a l'hora de fer una determinada creació però sembla que el tipus d'interrogació que pronuncia desconcerta els infants, potser per la forma en què es qüestionen algunes de les seves aportacions amb expressions com "home i voleu dir..." o bé per la insistència en formular el mateix tipus de pregunta en lloc d'intentar establir nous punts de contacte entre ells, l'obra i l'autor. 
Algunes qüestions que aporta la mestra poden originar reflexions interessants però, en general, es mostren molt més efectives si recullen idees que ja han expressat els alumnes. Algunes de les seves aportacions no generen debat, probablement per tal com estan formulades, i després d'una resposta breu i poc significativa els alumnes retornen a expressar els seus comentaris personals al voltant d'aspectes prou interessants. En canvi, quan la mestra enfoca les qüestions a partir de les intervencions dels infants, amb la pretensió d'aprofundir-les, les reflexions s'enriqueixen:

MESTRA: I el títol $\uparrow$ què diu el títol $\uparrow$

CÈLIA: Ah el títol és la lluna [d'en Joan]

XELL: [D'en Joan]

PEP: [D'en Joan]

MIQUEL: Sí $\downarrow$ però a mi m'ha fet sen- no m'ha fet sentir gaire bé quan un dia

l'acompanya la lluna i l'altre dia no tenia la lluna i veia per- els trons per la

finestra $\downarrow$ no m'ha agradat això $\downarrow$

CÈLIA: A mi tampoc

MESTRA: Per què devia passar això $\uparrow$

MIQUEL: Perquè com li havien [pres la salut]

XELL: [Perquè:]

MIQUEL: Al pare

XELL: Doncs per- deu ser perquè el pop li anava matant la salut $\downarrow$

CÈLIA: Sí $\downarrow$ sí clar

Aquest fragment del diàleg permet exemplificar com la primera pregunta de la mestra té poc sentit tal com es formula perquè els alumnes es limiten a repetir el títol del conte i no es produeix cap relació d'aquest aspecte literari amb el conjunt de l'obra. Els infants canvien de tema ràpidament $\mathrm{i}$ quan la docent intenta aprofundir en l'aportació que un dels alumnes ofereix, a partir del sentiment que li produeix un moment de l'obra, es construeix una interpretació interessant d'un passatge de l'àlbum il·lustrat a partir de les relacions entre el codi visual i textual. La idea, a més, es corrobora per una altra de les alumnes que respon afirmativament davant de les descobertes que li han ofert els seus companys. 
En altres ocasions la mestra recolza i indaga a partir d'aspectes que han aportat els alumnes, intentant aprofundir en les seves concepcions:

MARC: A mi m'ha agradat molt el- el títol per::perquè si llegeixes el- el títol no saps pas de què va el conte (..) només saps que va de dos fils MESTRA: XX No t'ho pensaves que passaria això eh $\uparrow$

PAULA: Jo- Jo al principi com que el títol posa "DOS FILS” ((@em pensava que eren dos fils que parlaven com passa a vegades als contes))

MESTRA: I en canvi què són els dos fils aquí $\uparrow$

PAULA: Els dos camins que fa en Moussa

MARC: $=$ A- amb el tren

L'exclamació que realitza la mestra en resposta a la sorpresa que manifesta en Marc, quan és capaç de recuperar les expectatives que li havia generat el títol i contraposar-les amb el sentit de l'obra, sembla possibilitar que una altra companya, la Paula, també es qüestioni les primeres idees que li havia suggerit el títol i manifesti les concepcions inicials que esperava, relacionant-les amb les seves experiències lectores, que difereixen de les transmeses per la lectura.

En la següent intervenció la docent interroga fins a descobrir quin paral·lelisme hi pot haver entre el títol i la narració, en aquest cas fent que el grup es pugui apropar a les funcions que pot fer el títol d'una obra des d'un punt de vista més poètic, suggerent, paradoxal o descriptiu.

SERGI: Com es titula (agafa el conte)(...) ai bueno la "Car:me So:lé Ve:drell” que és una catalana

MESTRA: [I el títol $\uparrow]$

MARC: [Es clar perquè-] La lluna d'en Joan

MESTRA: Què us sembla per què deu ser això $\uparrow$

PAULA: Perquè la lluna era com d'en Joan perquè el va ajudar molt

MARC: Sí a més eren amics

SERGI: I a més potser el seu fill de la Carme es deia Joan (..) i ha volgut fer un conte d'en Joan 
L'exemple mostra com la mestra aprofita un aspecte que l'alumne anomena però sobre el que no se'n produeixen reflexions, ja que sembla esmentar el títol quan en realitat es vol referir al nom de l'autora, per intentar aprofundir-hi. Aquest fet permet que alguns alumnes, com la Paula, estableixin relacions entre el títol i les accions de la narració. D’altres, com en Sergi, posen de manifest la figura de l'autor i les motivacions que el poden portar a prendre una o altra decisió en el procés de creació.

Les preguntes de la mestra poden suscitar múltiples respostes i endinsar-se en camins inesperats:

MESTRA: I això de parlar de la salut $\uparrow$ és com: què us a:sembla $\uparrow$

CÈLIA: A mi bé:

MESTRA: Això de què el pare perd la salut $\uparrow$

CÈLIA: A mi em sembla molt bé perquè té una altra història i una aventura

En aquest cas, formula una pregunta intentant comprovar de quina manera interpreten l'expressió "perdre la salut", com posen en joc els seus coneixements del món i les formes estètiques de contar-los literàriament, però la Cèlia respon a partir d'un coneixement metaliterari que mostra la detecció dels trets característics de les històries, entenent que l'eix central d'una narració gira al voltant de l'exposició d'un conflicte o d'una aventura.

\section{Conclusions}

El paper de la mediació en la formació literària es centra en el coneixement de les obres, però també en el disseny d'intervencions didàctiques basades en la creació de pràctiques estimulants que permetin que l'alumne s'adoni de com la literatura cerca la nostra implicació emotiva, interroga la nostra realitat des del llibre, estableix construccions entre els elements i utilitza detalls per a la construcció de sentits globals (Colomer 2001).

L'experiència portada a terme pretén contribuir a donar resposta a les qüestions plantejades inicialment sobre quin tipus de pràctiques resulten més útils per a l'aprenentatge literari, quines característiques han de tenir les propostes i quin paper ha d'exercir el docent en el desenvolupament de les activitats. 
D'entrada, sembla que el diàleg esdevé realment una tasca de formació rellevant si es desenvolupa a partir de fórmules o recursos que fomentin l'aprenentatge d'expressar-se, de parlar sobre les obres. La pauta és un instrument que permet desenvolupar la dinàmica de la conversa des de la perspectiva literària, com un punt d'inici que els alumnes i la mestra usen de forma lliure. Aquest material permet generar converses al voltant d'aspectes literaris que els alumnes no expressaven abans de la seva utilització, de manera que els resulta útil per concretar idees, aprofundir-les i expandirles.

Les aportacions de la mestra prenen importància sobretot per la forma en què es plantegen $\mathrm{i}$ el moment en què es formulen. Sembla clau que el disseny i el desenvolupament de les pràctiques educatives parteixin del protagonisme dels infants en el seu procés d'aprenentatge, de manera que els alumnes no depenguin passivament del docent.

En definitiva, l'eficàcia d'aquestes intervencions recau, en gran mesura, en la utilització de materials i recursos que permetin el desenvolupament d'aprenentatges, i no només el control de la realització de tasques, i augmentin la possibilitat que l'alumne esdevingui autònom, participant activament en el camí del seu aprenentatge. De la mateixa manera, cal destacar la importància que el mestre es mantingui atén a les propostes dels infants i sigui capaç d'afavorir la capacitat reflexiva dels alumnes al voltant del fet literari en tota la seva complexitat perquè els infants puguin convertir-se en lectors actius, creatius, en una determinada comunitat cultural.

\section{Referències bibliogràfiques}

Amat, V. (2010) Compartir per construir. Aprendre a valorar àlbums a Cicle Inicial. Articles de Didàctica de la Llengua i la Literatura, 52: 32-41.

Camps, A. i Colomer, T. (1998) Ensenyar a llegir, ensenyar a comprendre. Barcelona: Edicions 62.

Chambers, A. (2007a) El ambiente de la lectura. Mèxic: FCE.

- (2007b): Dime. Los niños, la lectura y la conversación. Mèxic: FCE.

Colomer, T. (1998) La formació del lector literari. Barcelona: Barcanova.

- (2001) La enseñanza de la literatura como construcción del sentido. Lectura y vida.

Revista Latinoamericana de lectura. Asociación Internacional de Lectura (IRA), 1: 6-23.

- (2005a) El papel de la mediación en la formación de lectores. Dins: Lecturas sobre lecturas, 3 : 1-44. Mèxic: FCE.

- (2005b) Andar entre libros. La lectura literaria en la escuela. Mèxic: FCE. 
- (2009) L'escola fa o desfà lecors? Revista Faristol, 64: 8-10.

Kiefer, B. (1999) Los libros-álbum como contextos para comprensiones literarias, estéticas y del mundo verdadero. Revista Parapara Clave El libro-álbum: invención y evolución de un género para niños, 1: 72-83.

Manresa, M. i Silva-Díaz, C. (2005) Dialogar per aprendre literatura. Dins: Dialogar per aprendre, Ribas, T. i Vilà, M. (coord.), pp. 50-56. Barcelona: Graó.

Ribas, T. i Vilà, M. (2005) Dialogar per aprendre. Dins: Dialogar per aprendre Ribas, T. i Vilà, M. (coord.), pp. 5-10. Barcelona: Graó.

Siro, A. (2005) El desafío de la continuidad: una mirada sobre la intervención del mediador en la formación de lectores de álbumes. Dins: Lecturas sobre lecturas, 17: 45-95. Mèxic: Conaculta.

Wells, G. (1988) Aprender a leer y escribir. Barcelona: LAIA.

\section{Apèndix}

\section{CRITERIS DE TRANSCRIPCIÓ}

S'intenta que les qüestions ortogràfiques no dificultin la lectura, però es mantenen les formes usades pels alumnes(ortografia, sintaxi i lèxic), amb la voluntat de reflectir la manera de parlar dels interlocutors.

\begin{tabular}{|l|l|}
\hline Després del nom de qui parla & $:$ \\
\hline Paraula o enunciat interromput & - \\
\hline Formulació de pregunta & $\uparrow$ \\
\hline Entonació descendent & $\downarrow$ \\
\hline Ėmfasis/Intensitat forta & MAJÚSCULA \\
\hline Allargaments sil·làbics & $: \quad:::$ \\
\hline Pausa curta & $\mathbf{( . )}$ \\
\hline Pausa de més de mig segon & $(.)$. \\
\hline Solapament & [text] \\
\hline Parla encadenada & $=$ \\
\hline Riure & $@$ \\
\hline Enunciat pronunciat rient & ((@) text afectat) \\
\hline Fragments incomprensibles & xxx \\
\hline Fragments llegits & “text” \\
\hline Comentaris del transcriptor & (comentari) \\
\hline & \\
\hline
\end{tabular}

Referència de l'autora

Vanesa Amat i Castells és mestra d'Educació Primària per la Universitat de Vic, Llicenciada en Humanitats per la Universitat Oberta de Catalunya i Màster de Recerca en Didàctica de la Llengua i la Literatura per la Universitat Autònoma de Barcelona. Ha exercit com a mestra en l'etapa d'educació primària i actualment és professora de Didàctica de la Llengua i la Literatura a la Facultat d'Educació de la Universitat de Vic. És membre del Grup de Recerca en Educació, Llenguatge i Literatura de la Universitat de Vic (GRELL) i col-labora en el Grup de Recerca de Literatura Infantil i Juvenil i Educació Literària de la Universitat Autònoma de Barcelona (GRETEL).

Ha participat en jornades i seminaris sobre ensenyament de la llengua i la literatura. Els seus projectes de recerca es centren en l'àmbit de la didàctica de la literatura infantil.

Email: vanesa.amat@uvic.cat 
1 Citat per Colomer, T. (2009) L'escola fa o desfà lectors? Faristol, 63: 8.

2 Al llarg de l'article s'usen els termes conversa, diàleg, discussió, intercanvi o interacció oral fent referència a les activitats d'elaboració de raonaments i d'intercanvi d'idees.

3 Els agrupaments es configuren tenint en compte la igualtat de gènere, és a dir, que en cadascun d'ells hi hagi el mateix nombre de nens que de nenes i la diversitat de coneixements, nivells i ritmes d'aprenentatge. En aquest sentit, tots els infants del curs elaboren prèviament una tasca individual on anoten algunes idees que els semblen interessants de les lectures d'àlbums il-lustrats llegits. La quantitat d'aportacions i especialment el seu grau d'aprofundiment s'utilitzen com a element de judici en l'organització d'agrupaments heterogenis. També es té en compte la diversitat d'origen en la procedència dels infants a l'hora de constituir els grups.

4 Lee, S. (2008) Espejo. Cádiz: Barbara Fiore.

Lionni, L. (2007) Neda-que-neda. Pontevedra: Kalandraka.

Molist, P. i Urberuaga, E. (2007) Dos fils. Barcelona: La Galera.

Solé, C. (2009) La lluna d'en Joan. Barcelona: Rosa Sensat.

5 Idees recollides a la pauta:

Bloc 1: El text és divertit/bonic/trist...

Hi ha rodolins, jocs de paraules, poemes...

M'ha costat d'entendre perquè feia servir paraules difícils

M'ha agradat aquesta frase:...perquè...

Bloc 2: Els personatges són...

Els personatges s'assemblen a mi..

S'assemblen a un conte que...

La història és per a nens petits...

Bloc 3: Els dibuixos són...

Els dibuixos m'han ajudat/no m'han ajudat a entendre la història

Té coses per tocar, obrir...

M'ha agradat aquest dibuix...perquè...

Bloc 4: He estat intrigat per saber el final...

El final de la història m'ha fet sentir...

Les aventures són molt/poc emocionants

És poc interessant perquè ja se sap què passarà

6 Es constata, en la línia del que apuntava Kiefer (1999), que el rol de l'artista i els diferents factors estètics són elements que els infants utilitzen a l'hora d'elaborar significat i donar valor a la creació. 